\title{
The challenges of sustaining measles elimination in Canada
}

\author{
Crowcroft NS ${ }^{1,2,3^{*}}$
}

1 Public Health Ontario, Toronto, ON

2 Laboratory Medicine and Pathobiology University of Toronto, Toronto, ON

3 Dalla Lana School of Public Health, University of Toronto, Toronto, ON

* Corresponding author: Natasha.crowcroft@oahpp.ca

\section{Abstract}

Recent importations of measles into Canada have not generally led to large outbreaks, indicating that measles is well controlled in Canada. Isolated large outbreaks that have occurred remind us of the need to remain vigilant. Measles presents particular challenges because it is the most infectious disease known, it thrives among those who do not access the child health system for one reason or another, and we do not always have the information we need to identify and target communities with low immunization coverage. Outbreaks typically arise from Canadians who travel and are exposed to measles abroad. Controlling sporadic outbreaks arising from importations is time and resource intensive, which makes immunization for Canadians travelling outside the region of the Americas (where measles has been eliminated) a priority. To prevent importations of measles into Canada altogether requires other countries and regions of the world to make progress in eliminating measles.

Recent importations of measles into Canada are actually a reminder of the amazing success of immunization in eliminating this disease. This is because, with a few notable exceptions, the majority of importations have either not led to further cases or have caused only small outbreaks, indicating that, overall, measles is currently well controlled in Canada (1). The size of outbreaks (including cases that have no onward transmission) can be used to estimate level of control through calculation of the effective reproduction number $(R e)$, defined as the average number of people actually infected by each case during a specified time period in a population that has some level of immunity (2). Provinces such as Ontario, in which a single case is defined as an outbreak, can calculate Re. Analysis of data from 13 outbreaks in 2009-12 revealed an estimated Re of 0.52 , well below the epidemic threshold of $\operatorname{Re}=1$ (3).

Recent outbreaks of measles in Canada have included typical cases characterized by fever, cough and a maculopapular rash. Patients have been hospitalized, but fortunately there have been no deaths. In 2011, 10 measles deaths occurred in France during a year when epidemics of measles exploded across Europe, with over 30,000 cases reported to the European Centre for Disease Control $(4,5)$. Following repeated importations from the 2011 epidemic in Europe, Quebec had the largest outbreak of measles of any country in North, Central or South America since 2001, reaching a total of 776 cases between 2011 and 2012. This threatened the elimination status of the whole region (6). The main cause of the outbreak was a level of immunization coverage lower than what was needed for elimination (6), an example of why jurisdictions cannot be complacent and why they need high-quality data on coverage, down to district level and in all age groups, to identify areas at risk and take effective action when gaps in immunity are identified.

We know that gaps in immunity exist in communities that reject immunization or in areas where coverage is just not high enough. Questions that arise about the exact level of immunization coverage and population immunity cannot be answered in the absence of a vaccine registry or sero-surveillance. The fact that three-quarters of cases in 2013 were unimmunized may indicate that coverage is lower than we think, since we would expect most cases to be vaccinated if coverage were high.

Measles presents a particular challenge because it is the most infectious disease known, with a basic reproduction number of around 17 (meaning that in a fully susceptible population, each infected person would, on average, infect 17 others). Population immunity above $95 \%$ is therefore needed for elimination (7). Allowing for vaccine failures, this means our system has to reach $97 \%$ two-dose coverage to sustain elimination, a 
stringent test of the child health system. There is no place to hide from measles, and sooner or later the virus will seek out anyone who is susceptible. This was beautifully demonstrated in the 2013 outbreak of measles in Alberta, in which every person who was exposed and was unimmunized or had no history of measles became infected (8). Outbreaks that have occurred over recent years illustrate how measles immunization coverage needs to be both high and uniform, and how susceptible people cluster together non-randomly. Ascertaining coverage by school and community, as exemplified for southern Alberta, reveals the variation and gaps in immunity and allows public health to develop targeted strategies for improving coverage and plan for outbreaks (9).

Measles shines a light on those who do not access the child health system for one reason or another, including religious groups who reject immunization, children of vaccine-hesitant parents and marginalized groups such as indigenous peoples. Indicators relating to measles immunization programs (coverage, measles mortality) are used as a child health system quality indicator of access to basic public health and primary care, for example as part of the Millennium Development Goals. This approach can be used to compare Canada with other countries, as typified in UNICEF's report on child and maternal well-being, in which Canada ranked at 28 out of 29 countries because of immunization coverage (10). Clearly there is room for improvement. Extremely high quality data are needed at granular levels to be able to demonstrate that we are sustaining control: methods used in the National Immunization Coverage Survey that reach a sample of the population by telephone may be inadequate for this purpose, because responders may not be representative of the general population or be numerous enough to represent smaller communities. Communities that have either not had access to immunization or reject immunization may be small but still large enough to reach the critical community size $(250-400,000)$ required for sustaining measles transmission (11). Religious communities that do not accept immunization may be exposed to measles through their strong links to regions where measles has not been eliminated. We can learn from approaches taken in the Netherlands, where local immunity data were used to explore the impact of vaccination heterogeneity in religious communities linked with those in Canada, and predicted the large outbreak that emerged in the Netherlands in $2013(12,13)$.

Rather than being stigmatized as a possible source of risk, immigrants to Canada may actually be important in reducing the risk of measles within this country. While nearly $20 \%$ of Canadians were born outside Canada, most came from measles-endemic countries and would have arrived here immune, as a result of having had measles in childhood. As citizens, they are also more likely to be immunized (14). Furthermore, most imported cases have been linked to Canadians who travelled abroad and brought measles back rather than to visitors to Canada (1). This is good news, since Canadians should be easier to reach than visitors, to ensure that they and their children are adequately protected from measles before travel.

Importations are expected as long as measles continues to circulate in other regions of the world. Sustaining measles elimination in the face of such importations is time consuming and expensive, and includes the extensive work of following up cases and contacts and controlling outbreaks. Figures are not available for Canada, but in the United States (US) the cost to public health departments of responding to measles outbreaks in 2011 was US\$2.7-5.3 million (15). In this work, a marriage of good public health microbiology and epidemiology is the definition of high-quality measles surveillance and outbreak response. The Public Health Agency of Canada's National Microbiology Laboratory plays an excellent role through genotyping measles cases and is well positioned to deliver the whole genome sequencing that will be needed to provide molecular evidence of the origin of cases (16).

International partnerships, including liaison with the Pan-American Health Organization (PAHO - the regional branch of the World Health Organization [WHO]), are critical to maintaining elimination of measles. In highly decentralized federal countries such as Canada, public health roles are shared among several levels of authority. This can present a barrier to global partners such as PAHO. The Public Health Agency of Canada is responsible for reference laboratory services and reporting weekly to $\mathrm{PAHO}$, but the provinces and territories work with local public health agencies to deliver surveillance and outbreak response. Canada can help in setting an example to the world of how all responsible levels of public health can work together seamlessly and successfully. The US supported the drive to eliminate measles in the region of the Americas in order to reduce the burden of imported measles, and recognizes the value to Americans of controlling measles in other regions (17). Now that measles is being predominantly imported from other regions, it may be time for Canada not only 
to sustain elimination within her own borders but also to work with $\mathrm{PAHO}$ in our region and WHO globally to support other regions of the world in eliminating measles. In controlling measles, Canada is fulfilling its global obligations. Importations will not cease, however, until measles is eliminated in all the countries of the world.

Ultimately this will prevent importations altogether, reduce costs and save lives everywhere.

\section{References}

(1) Shane A, Hiebert J, Sherrard L, Deehan H. Measles surveillance in Canada: Trends for 2013. CCDR 2014:40-12,195.

(2) De Serres G, Gay NJ, Farrington CP. Epidemiology of transmissible diseases after elimination. Am J Epidemiol 2000; 151:1039-1048; http://aje.oxfordjournals.org/content/151/11/1039

(3) Lim GH, Deeks SL, Fediurek J, Gubbay J, Crowcroft NS. Documenting the elimination of measles, rubella and congenital rubella syndrome in Ontario: 2009-12. CCDR 2014:40-8.

(4) Number of cases of measles reported to The European Surveillance System (TESSy) by EU and EEA countries, 2011. http://www.ecdc.europa.eu/en/healthtopics/measles/epidemiological_data/Pages/Number-ofmeasles-cases-2011.aspx

(5) Antona D, Levy-Bruhl D, Baudon C, Freymuth F., Lamy M, Maine C, et al. Measles elimination efforts and 2008-2011 outbreak, France. Emerg Infect Dis. 2013;19(3):357-64

(6) De Serres G, Markowski F, Toth E, Landry M, Auger D, Mercier M, et al. Largest measles epidemic in North America in a decade--Quebec, Canada, 2011: contributions of susceptibility, serendipity, and superseeding events. J Infect Dis. 2013;207(6):990-8

(7) Gay NJ, Hesketh LM, Morgan-Capner P, Miller E. Interpretation of serological surveillance data for measles using mathematical models: implications for vaccine strategy. Epidemiol Infect. 1995;115(1):139-56.

(8) Kershaw T, Suttorp V, Simmonds K, St. Jean T. Outbreak of measles in a non-immunizing population in, Alberta, October-November 2013. CCDR 2014:40-12,219.

(9) Matkin A, Simmonds K, Suttorp V. Measles-containing vaccination rates in Southern Alberta. CCDR 2014:40-12, 212.

(10) Stuck in the middle. Child Well-Being in Rich Countries: A comparative overview. Unicef Canada. Accessed 16th May 2014 http://www.unicef.ca/sites/default/files/imce_uploads/DISCOVER/OUR\%20WORK/ADVOCACY/DOMESTIC/ POLICY\%20ADVOCACY/DOCS/unicef_rc_11_canadian_companion.pdf

(11) Keeling MJ, Grenfell BT. Disease extinction and community size: modeling the persistence of measles. Science. 1997;275(5296):65-7

(12) Glass K, Kappey J, Grenfell BT. The effect of heterogeneity in measles vaccination on population immunity. Epidemiol Infect. 2004;132:675-683

(13) Mollema L, Smits GP, Berbers GA, Van Der Klis FR, Van Binnendijk RS, De Melker HE, Hahné SJ. High risk of a large measles outbreak despite 30 years of measles vaccination in The Netherlands. Epidemiol Infect. 2014 May;142(5):1100-8.

(14) Quach S, Hamid JS, Pereira JA, Heidebrecht CL, Deeks SL, Crowcroft NS, Quan SD, Brien S, Kwong JC; Influenza vaccination coverage across ethnic groups in Canada. Public Health Agency of Canada/Canadian Institutes of Health Research Influenza Research Network Vaccine Coverage Theme Group.CMAJ. 2012 Oct 16;184(15):1673-81. doi: 10.1503/cmaj.111628. 
(15) Ortega-Sanchez IR1, Vijayaraghavan M2, Barskey AE2, Wallace GS2Vaccine. 2014 Mar 5;32(11):1311-7. doi: 10.1016/j.vaccine.2013.10.012. Epub 2013 Oct 14. The economic burden of sixteen measles outbreaks on United States public health departments in 2011

(16) Hiebert J, Severini A. Measles molecular epidemiology: What does it tell us and why is it important? CCDR 2014:40-12, 233.

(17) CDC. Manual for the Surveillance of Vaccine-Preventable Diseases. Chapter 7 Measles.

http://www.cdc.gov/vaccines/pubs/surv-manual/chpt07-measles.html 